\title{
The Introduction of New Scale and Corrosion Inhibitor of Central Air Conditioning Circulating Cooling Water
}

\author{
Maodong Li \\ Guangzhou Special Pressure Equipment Inspection and \\ Research Institute \\ Guangdong, China \\ e-mail: 2453962572@qq.com \\ Jianfeng Xiao \\ Changsha University of Science \& Technology \\ Changsha, China \\ e-mail: Xjf74@sina.com
}

Sixue Guo

Guangzhou Special Pressure Equipment Inspection and

Research Institute

Guangdong, China

e-mail: 71456341@qq.com

\author{
Junming Zhao \\ Guangzhou Special Pressure Equipment Inspection and \\ Research Institute \\ Guangdong, China \\ e-mail: broodzjm@126.com \\ Yingtong Chen \\ Guangzhou Special Pressure Equipment Inspection and \\ Research Institute \\ Guangdong, China \\ 332034523@qq.com
}

\begin{abstract}
In this paper, an review of common water scale and corrosion inhibitor of central air circulating cooling is given. The focus is on the mechanism of scale and corrosion inhibitor. Indicates the status of research to scale and corrosion inhibitor at home and abroad. At the same time, some existing problems of scale and corrosion inhibitor was found. And prospects for its development prospects was given, which shows that the scale and corrosion inhibitor will develop in the direction toward the green and environmentfriendly type at the future.
\end{abstract}

Keywords-central air conditioning; scale inhibitor; corrosion inhibitor; water treatment; green.

\section{INTRODUCTION}

With the rapid growth of economic and the continuous improvement of people's living standards, the central airconditioning systems have become essential for all kinds of high-grade building. Most of the central air conditioning system use recycled water, which is made up of open and closed recycled water systems. Central air conditioning cooling water system, an open-loop system, is made up of cooling water circulation pumps, pipelines, cooling towers, refrigeration unit chillers and sump etc. Cooling water is an open-loop system, the water temperature is generally between $30 \sim 40{ }^{\circ} \mathrm{C}$. In the system during normal operation, due to the impact of weather and the environment, the dust, impurities and suspended solids in the air are into the system by the cooling tower, deposited in the condenser, form the dirt, and impact the unit's heat transfer efficiency.

High-temperature cooling water continuously evaporate to the atmosphere by cooling tower, resulting in the cooling water concentrated. So it makes a lot of calcium and magnesium ions in water precipitated, forming the scale $\left(\mathrm{CaCO}_{3}, \mathrm{MgCO}_{3}\right)$ adhered to the surface of the heat exchanger and impacting of heat transfer.

In order to prevent forming scale and corrosion of equipment and piping, improve thermal efficiency, save energy and extend the life of the equipment, it is necessary to improve the quality of central air circulating water. The way added water chemicals (scale inhibitors, corrosion inhibitors, biocides) to the circulating cooling for controlling scale was took at home and abroad, which is currently the most widely used for air-conditioning water treatment [1]. The common scale and corrosion inhibitors of central air conditioning cooling water mainly include polyphosphates, organic phosphorus and copolymers. These scale and corrosion inhibitors are with economical efficient features, but with poor biodegradability, and can cause eutrophication and serious pollution of the water when phosphorus-containing substances released into the environment[2]. With the people's environmental awareness improved, developing a new type of green and phosphorus (phosphorus) scale and corrosion inhibitor has become a major problem to be solved in current environmental protection and water-treatment chemicals.

\section{THE MECHANISM OF CENTRAL AIR CONDITIONING CIRCULATING WATER-TREATMENT CHEMICAL}

Performance evaluation and mechanism of scale and corrosion inhibitor is the key issues in the basic research of circulating cooling water treatment. Because the complex physical and chemical processes involved, there is no consensus of opinion on this drop academia. The research in this area are more concentrated in experiment. Although making some advances [3], but it failed to reveal the nature of the problem. Compared with experimental work, there 
was relatively few theoretical studies at the molecular level to scale and corrosion inhibition mechanism. Because the molecular structure have a decisive impact on the pharmaceutical properties, if the mechanism is clarified, it will provide theoretical guidance for the design of new agents. Shuguang- Zhang, etc. using quantum chemistry, molecular dynamics method systematically for scale and corrosion inhibition system [4], have got some achieves with some guiding role to synthesis of some new chemical.

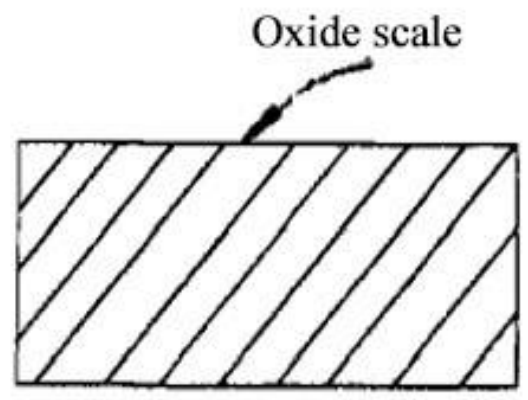

(a)Oxide protective scale

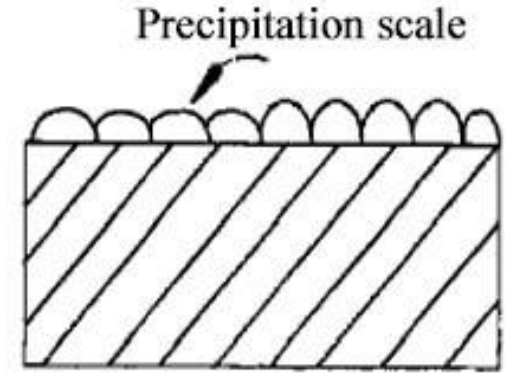

(b)Precipitate protective scale

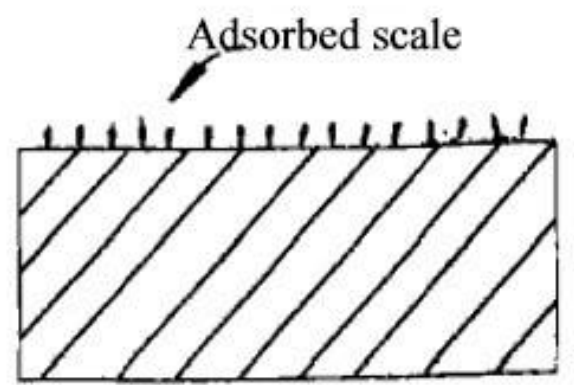

(c)Adsorbed protective scale

Figure 1. Three different types of the protective film.

\section{A. Scale Inhibition Mechanism}

In cooling water systems or other heating surface, scale formation must contain salt crystals precipitate. So, the scale formation is affected by the three steps of the formation of crystals: (a) supersaturated solution; (b) generating crystal nuclei; (c) crystal nuclei growing; (d) crystals forming. If any of the three steps is prevented, the process of scale formation is suppressed or slowed down. And the role of scale inhibition is to this one or several steps. Many studies [5] have pointed out that Phosphoric acid, polyphosphoric acid and the other scale inhibitors can be adsorbed to the calcium carbonate microcrystals (less than the critical radius of the crystal) by physical or chemical action, and the interface energy can be improved. Thus, it is increased that the energy need to overcome by supersaturated solution of calcium carbonate forming calcium carbonate crystallization. Therefore, the supersaturated solution, forming crystals under normal circumstances, may not appear crystal since the inhibitor is added. Only the degree of supersaturation of the solution to further improve, it can appear crystal center. The basic physical and chemical processes that scale inhibitor interfere crystal growth are chelated reactions and surface adsorption. Scale inhibitor lets the solid particles of water suspended in the water by adsorption, and other bridging flocculation, which prevents agglomeration and sedimentation [6].

\section{B. The mechanism of Corrosion Inhibition}

In the open-cycle cooling water system, the water is in contact with air and oxygen in the water can reach saturation. Because of the unevenness of the surface of the metal and the conductivity of the water, some chemical reactions occur, which corrode the mental surface and produce a large amount of corrosion products within the tube.

Anodic reaction

Cathodic reaction

$2 \mathrm{Fe} \rightarrow 2 \mathrm{Fe}_{2}++4 \mathrm{e}$

The overall reaction

$\mathrm{O}_{2}+2 \mathrm{H}_{2} \mathrm{O}+4 \mathrm{e} \rightarrow 4 \mathrm{OH}$

$2 \mathrm{Fe}+\mathrm{O}_{2}+2 \mathrm{H}_{2} \mathrm{O} \rightarrow 2 \mathrm{Fe}(\mathrm{OH})_{2}$
When the corrosion occur, Iron generate ferrous hydroxide and precipitate out of solution. However, this ferrous compound is unstable in the cooling water with oxygen. It will be further oxidized to form ferric hydroxide.

$2 \mathrm{Fe}(\mathrm{OH})_{2}+\mathrm{H} 2_{\mathrm{O}}+1 / 2 \mathrm{O}_{2} \rightarrow 2 \mathrm{Fe}(\mathrm{OH})_{3} \downarrow$

Then, Ferric hydroxide dehydration, generating rust.

$2 \mathrm{Fe}(\mathrm{OH})_{3} \rightarrow \mathrm{Fe}_{2} \mathrm{O}_{3} \downarrow+3 \mathrm{H}_{2} \mathrm{O}$

$\mathrm{Fe}(\mathrm{OH})_{3} \rightarrow \mathrm{FeOOH} \downarrow+\mathrm{H}_{2} \mathrm{O}$

Usually, the $\mathrm{PH}$ values of natural freshwater is 6.0 to 8.4 and 7.0 to 8.4 for seawater. The $\mathrm{PH}$ value of open-loop cooling water, in the normal operation, is in the range of 4.3 to 9.0. The corrosion rate is parallel to the axis of $\mathrm{PH}$ value. In the other words, the corrosion rate is insignificant change in this $\mathrm{PH}$ range. The main cause of corrosion is the depolarization of oxygen.

From the point of view of electrochemistry, corrosion inhibitors, adsorbed on the metal surface, can separately or simultaneously inhibit the anode, cathode reaction, and reduce the corrosion current for achieving the purpose of corrosion. According to the type of corrosion inhibitor to form protective scale, inhibitor is divided into oxide scale type, adsorption scale type and deposition scale type. As the difference of electrode process, corrosion is divided into anode type inhibitor, cathodic type inhibitor and mixed type. Mechanism of anodic corrosion inhibitor is that anodic polarization increases, the corrosion potential moves in the positive direction and the anodic reaction rate reduces. The mechanism of cathode is that the cathodic polarization increases and the hydrogen evolution overpotential cathodic reaction increases. The insoluble or colloidal substances, generated by the reaction of mixed inhibitor and medium (or metal iron), deposited on the anode and the cathode region, which not only hinder the dissolution of the anode metal, but also hinder the oxygen closing to the cathode and reduction reaction occurring [7]. 
TABLE I.

OMMON INHIBITOR CLASSIFICATION

\begin{tabular}{ll}
\hline \multicolumn{1}{c}{ Category } & \multicolumn{1}{c}{ Common Pharmacy } \\
\hline Oxide scale & $\begin{array}{l}\text { Sodium chromate, sodium nitrite, sodium molybdate, } \\
\text { tungstate and tungsten heteropolyacid }\end{array}$ \\
\hline $\begin{array}{l}\text { Precipitation } \\
\text { scale }\end{array}$ & $\begin{array}{l}\text { Hexametaphosphate, sodium tripolyphosphate, sodium } \\
\text { silicate, zinc sulfate, sodium metaborate, EDTMP, } \\
\text { sarcosine }\end{array}$ \\
Adsorption & $\begin{array}{l}\text { Hexadecylamine, wooden acid sodium, glucose sodium, } \\
\text { scale }\end{array}$ \\
\hline
\end{tabular}

III. THE RESEARCH STATUS OF CORROSION INHIBITOR AT HOME AND ABROAD

\section{A. China's development status of scale and corrosion inhibitor}

The main contents of water quality and stability are corrosion inhibitor, scale inhibitor, killing and slime inhibitor, which is closely related to several factors and complement each other. Study of water treatment chemicals in China started late. At so far, China have developed a tradition of phosphate formula, phosphoruscontaining compound formula, phosphorus-based alkaline water treatment formula, all organic formula, aluminate formula and silicate formula. China began to develop acid / polylactic acid lipid copolymer at 1980s and carboxylic / sulfonic acid copolymer at 1990s. Corrosion inhibitors currently used in the industry is mainly polylactic acidbased copolymer. In China, circulating cooling water system is more realistic in pharmaceutical and formulation. Corrosion and scaling have different degrees of improvement at all system. The management level of circulating water has been significantly improved, and achieved good economic and social benefits [8].

\section{B. Development of foreign corrosion inhibitor}

Foreign corrosion inhibitor experienced the development process of inorganic, organic and green scale and corrosion inhibitor. Inorganic scale and corrosion inhibitor started earlier, mainly including chromate formula, nitrate formula, nitrite formula, polyphosphates formula, silicates formula and borate formula. Chromate, nitrite, polyphosphates and borates have been eliminated because of their toxic and pollution. 2Hydroxyphosphonocarboxylic Acid (HPAA) and other organic phosphate compound was developed in the late 1980s [9]. The Copolymer of phono and carboxylic acid in the 1990s, which had low phosphorus content and solved the problem of eutrophication. In recent years, the United States based on the development of water treatment corrosion inhibitor of organic adsorption with litter toxicity, low toxicity, good biodegradability and easy environmental accept. Many natural polymers and biopolymer materials get better use. Biopolymers polyaspartic acid (PASP), good inhibition effect and harmless to the environment, can be used as dispersants, scale inhibitors, corrosion inhibitors and detergent additives, etc. Compared with traditional corrosion inhibitors, polyaspartic acid is a good scale and corrosion inhibition, highly biodegradable and the green chemicals. Foreign Kakuchi $\mathrm{T}$ [10] and others was in deep research and found out some good synthesis methods. Recent studies said tributylamine, AMBT, ATR, ARH and other organic amines has excellent corrosion inhibition to the metal in acidic medium [11].

\section{THE DEVELOPMENT DIRECTION OF GREEN SCALE AND CORROSION INHIBITOR}

As a specialty chemicals water treatment corrosion inhibitor in green, it is its production raw materials and conversion agent in green, and the key is its product of target molecule in green. Water scale and corrosion inhibitor of green can start from the following aspects:

\section{A. Be complex on existing green scale and corrosion inhibitors}

Various water treatment scale and corrosion inhibitor has own shortcomings, and the application of its single component is limited. For better corrosion and scale effect, we can take advantage of synergies in principle. Based on the current products of corrosion inhibitor, we can develop complex corrosion and scale inhibitor system. a The single inhibitor specie for complex choices has zinc salt, sodium molybdate, sodium tungstate, sodium gluconate, polyaspartic acid and phosphoric acid carboxylic acid [12].

\section{B. Modify to the existing scale and corrosion inhibitor}

Modification of the existing inhibitor is a leading shortcut in green. Because the polyacrylic acid scale inhibitor, although with a good performance, is difficult to biodegrade, it does not belong to the green water treatment agent. If insert the oxygen atoms in its molecular chain for modification, we can get the products both with excellent scale inhibition and easy biodegradable.

\section{EXPECTATION}

Throughout the research status of domestic and international green scale and corrosion inhibitor, future research directions to green scale inhibitor should be the following aspects: (1) improve the quality of existing products and reduce costs for a versatile, efficient, inexpensive, non-toxic or low toxic water treatment agent. (2) Strengthen the research between structure and properties for water treatment technology to be innovative, breakthrough. (3) Combine with the actual situation for the development of water treatment agent with low phosphorus or micro phosphorus. As long as the total emissions in line with environmental standards and less impact on the environment, we can use as a green water treatment agent.

\section{REFERENCES}

[1] Cooper K W, R A Erth, "Centrifugal water chilling systems, focus on off design Performance," Heating/ Piping/ Air Conditioning, Jan.2008, P63-67.

[2] Defang-Zeng, Jianguo-Li, "Development and application of an environmentally friendly corrosion inhibitor of phosphorus,' Cleaning World, Mar. 2010, pp.22-27.

[3] Abed Y, Kissi M, Hammouti B, "Peptidic compound as corrosion inhibitor for brass in nitric acid solution," Progress in Organic Coatings, vol.50, 2004, pp.144-147.

[4] Qian-Xie, "Corrosion Inhibitor GD-318 Research and Application," Industrial Water Treatment, vol. 28(10), 2008, pp. 56-87.

[5] Youbing-Yan, "Screening and industrial application of corrosion inhibitor," General corrosion control, vol. 19(4), 2005, pp. 22-27.

[6] Defang-Zeng, "Experimental study of environmentally friendly non-phosphorus corrosion inhibitor," Beijing Water Affairs, Apr. 2008, pp. 44-45. 
[7] Jinyong-Li, Development and mechanism of environmentally friendly corrosion inhibitor [D], Wuhan University of Technology, 2008.

[8] Yongmei-Yuan, "Circulating cooling water treatment chemical system present and future situation," Science and Technology Consulting Herald, vol. 4(4), 2003, pp.288-291.

[9] Ross R J, Low K C, Shannon J E, "Polyaspartate scale inhibitors biodegradable Alternatives to polyacrylates," Material performance, vol. 36(4), 2007, pp.53-57.

[10] Kakuehi T, Shibata M, Matsunami, "SSynthesis and charcterization of Poly(Sueeinimide-CO-6-aminoeaproic) acid byacid catalyzed Polycondensation of LasPartic aeid and 6aminoeaproieAeid," Joumal of Polymer Seienee Part A, vol. 35, 2007, pp. 285-289.

[11] Cruz J Garcia, Oehoa, Eeastro, "Experimental and theoretical study of the 3-a mino-1,2,4-tirazoleand-aminothiazole eorrosion inhibitors in earbon steel," Joumal of the Elcetrochemical Soeiety, vol. 150(1), 2003, pp. 26.

[12] Zifeng-Wu, Fangliang-Zeng, Xiangdong-Liu, "Green chemicals and non-phosphate corrosion inhibitor," Chemistry Journal, vol. 19(71), 2005, pp. 44-48. 